\title{
Pękanie szyn tramwajowych spawanych termitowo
}

\author{
The cracking tram rail of thermite welding
}

\section{Streszczenie}

Dzisiaj tory kolejowe i tramwajowe wykonuje się jako bezstykowe. Odcinki szyn łączy się trwale spawając je na przykład termitowo. Stale stosowane na szyny należą do stali trudno spawalnych. Między innymi dlatego, pomimo dużego postępu w dziedzinie spawania termitowego, wciąż zdarzają się przypadki pękania szyn w czasie ich spawania lub podczas eksploatacji. W artykule omówiono jeden z takich przypadków pękania szyn tramwajowych. Autorzy podkreślają, że główną przyczyną powstawania pęknięć w obszarze szyjki szyny są naprężenia cieplne (spawalnicze). Zwracają również uwagę na to, że powstawaniu takich pęknięć sprzyjają, na przykład wtrącenia niemetaliczne i mała praca łamania. Na podstawie wyników badań wytrzymałościowych, mikrostrukturalnych i fraktograficznych oceniono stan szyn i przeprowadzono analizę pod kątem występujących pęknięć. Przed montażem szyn na torowisku nie są wymagane badania mikrostrukturalne i wytrzymałościowe mające na celu określenie ich właściwości w tym zakresie. Autorzy zwracają uwagę na konieczność podjęcia prac w zakresie obowiązujących przepisów dotyczących badań i odbiorów torów tramwajowych.

Słowa kluczowe: spawanie termitowe; szyny tramwajowe; pękanie szyn; właściwości mechanicznet

\begin{abstract}
Nowadays, railway and tram rail tracks are made jointless. Rail segments are joined permanently, for example, by means of thermite welding. Steels out of which rails are made belong to the category of difficult-to-weld steels. That is one of the reasons why, despite major development in the realm of thermite welding, incidents of cracking in the course of welding or subsequent usage of the rails still occur. One of such incidents of tram rail cracking is discussed in the article. The authors stress that the main reason why cracks appear in the area of rail web is (welding) thermal stresses. They also point out that such factors as non-metallic inclusions and low impact strength are also conducive to the occurrence of cracks. On the basis of strength tests as well as microstructural and fractographic examination, the condition of the rails was evaluated, and they were analysed for crack occurrence. Neither microstructural examination nor strength tests that would determine the relevant characteristics of the rails are needed prior to their assembly in the subgrade. The authors call attention to the necessity of taking actions in the realm of applicable provisions of law concerning examination, testing and commissioning of tram rails.
\end{abstract}

Keywords: thermite welding; railway; tram rail; cracking; mechanical properties

\section{Wstęp}

Historia spawania szyn z wykorzystaniem reakcji termitowej rozpoczyna się na przełomie dziewiętnastego i dwudziestego wieku. W ostatnim roku dziewiętnastego wieku wykonano tą metodą pierwsze spawanie szyn na torach linii tramwajowej, a pierwsze spawanie szyn kolejowych pięć lat później [1]. Kolejność taka nie jest przypadkowa, wynika ona bezpośrednio z większej stabilności i mniejszych obciążeń torów tramwajowych oraz mniejszych prędkości pojazdów poruszających się po nich, w porównaniu do torów kolejowych. Dzisiaj, po ponad stu latach można powiedzieć, że dokonał się ogromny postęp w dziedzinie termitowego spawania szyn, w zakresie materiału szyn, mieszanek termitowych, technologii spawania, oprzyrządowania i kontroli spoin $[1 \div 4,9]$. Opracowane nowoczesne metody łączenia szyn są obecnie stosowane jako standard w czasie modernizacji starych torowisk i wykonywania nowych linii komunikacyjnych. Wytwarzane bezstykowe tory gwarantują większy komfort podróży i pozwalają na większe prędkości pojazdów przy jednoczesnym zwiększeniu trwałości szyn, podkładów i innych elementów torowiska. W PN-EN 13674-1 podano składy chemiczne i własności mechaniczne dziewięciu stali stosowanych na szyny kolejowe. Pierwsza z wymienionych stali R200 i ostatnia R400HT mogą zawierać węgla odpowiednio: 0,40 - 0,60 \% i 0,88 - 1,07\%. Dla tych stali, przy uwzględnieniu tylko średnich zawartości węgla i manganu, równoważnik węgla CEV jest równy odpowiednio: 0,66 \% i 1,17\%. Właściwości sześciu stali stosowanych na szyny tramwajowe podano w normie PN-EN 14811+A1. Dla przykładu, równoważnik węgla stali R260, obliczony jak powyżej, ma wartość $0,89 \%$. Na podstawie obliczonych wartości równoważnika węgla można powiedzieć, że stale stosowane na szyny tramwajowe i kolejowe należą do stali trudno spawalnych $[5,6]$. Między innymi dlatego, pomimo tak dużych osiągnięć w zakresie termitowego spawania szyn, wciąż pojawiają się przypadki pękania szyn w czasie ich spawania lub podczas eksploatacji [8]. Pęknięcia szyn, jeżeli nie zostaną wykryte

Dr inż. Michał Kawiak; dr inż. Sebastian Fryska - Zachodniopomorski Uniwersytet Technologiczny w Szczecinie.

Autor korespondencyjny/Corresponding author. michal.kawiak@zut.edu.pl 
i usunięte, mogą doprowadzić do groźnej w skutkach katastrofy. W artykule omówiono przykład pękania szyn rowkowych podczas spawania termitowego. Zwrócono uwagę na właściwości szyn sprzyjające powstawaniu pęknięć.

\section{Przykład peknięcia szyny tramwajowej powstałego podczas spawania termitowego}

Na terenie budowy torowiska, odcinki szyn tramwajowych o długości $18 \mathrm{~m}$, łączy się trwale spawając je na przykład termitowo, otrzymując tor bezstykowy. Na rysunku 1 pokazano wycinek szyny rowkowej ze złączem spawanym. W połowie wysokości szyjki szyny widoczne jest poziome pękniecie przechodzące przez spoinę i biegnące od niej na lewo i prawo. Po odcięciu lewego i prawego końca, wycinek szyny rozpadł się na dwie części. Dolną część, zawierającą stopkę szyny, pokazano na rysunku 2. Na powierzchni pęknięcia widoczna jest wada spawalnicza (ciemniejsze pole), którą można uznać za prawdopodobne miejsce inicjacji pęknięcia. Natomiast to, że pęknięcie ma tak znaczne wymiary, przebiega na wskroś szyny i ma długość ponad 200 mm, tłumaczyć można działaniem naprężenia cieplnego o znacznej wartości.

Opisany przypadek pęknięcia szyny tramwajowej podczas spawania termitowego nie jest jedynym. Na różnych stronach internetowych można znaleźć wiele takich przykładów. W Łodzi, Olsztynie i Szczecinie, na przełomie roku 2015/2016, na nowo wybudowanych lub zmodernizowanych liniach tramwajowych pękły szyny pod przejeżdżającym tramwajem. W każdym przypadku, po wypadnięciu fragmentu szyny, w torze powstawała wyrwa o różnej długości. Szczęśliwie pęknięcia szyn nie doprowadziły do katastrofy z pasażerami. Po tych zdarzeniach, na szynach przeprowadzono badania i stwierdzono ogółem kilkaset pęknięć o różnych wymiarach. W Łodzi wykryto ich 90 [7]. Wszystkie pęknięcia są poziome i leżą mniej więcej w połowie wysokości szyn, w miejscu ich spawania. Można zadać pytanie, czy tak duża ilość pęknięć powstała podczas krótkiej kilkumiesięcznej eksploatacji a może już podczas spawania szyn?

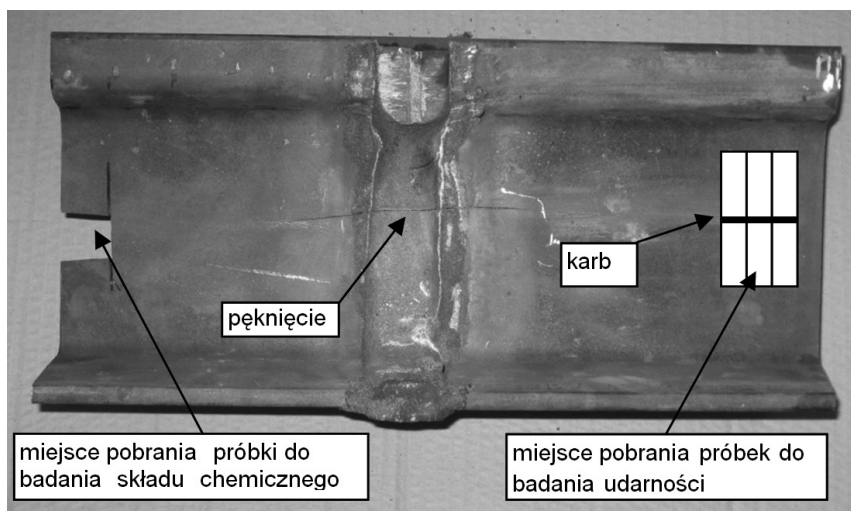

Rys. 1. Wycinek rowkowej szyny tramwajowej pękniętej podczas spawania termitowego

Fig. 1. Fragment groove tram rails broken during thermite welding

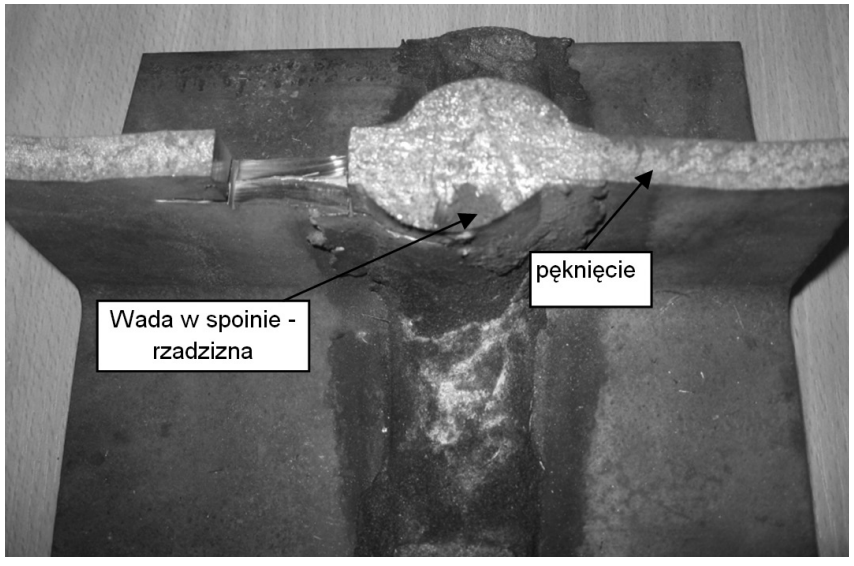

Rys. 2. Dolna powierzchnia pęknięcia od strony stopki szyny Fig. 2. The bottom surface cracks from the foot rail

\section{Badania laboratoryjne szyn}

Bezpieczeństwo ruchu pociągów i tramwajów w dużej mierze zależy od jakości szyn. Muszą one spełniać wymagania PN-EN 13674-1 lub PN-EN 14811+A1, dotyczące składu chemicznego, struktury, wytrzymałości zmęczeniowej i doraźnej. Z pękniętej szyny ze stali R260 (rys.1) pobrano próbki do badań zgodnie z PN-EN 14811+A1, z miejsc leżących w obszarze główki szyny, równolegle do kierunku jej walcowania. Skład chemiczny oznaczono na spektrometrze optycznym z wyładowaniem jarzeniowym GDOES. Zawartość pięciu pierwiastków, od węgla $C$ do siarki $S$ (tab. 1), odpowiada wymaganiom PN-EN 14811+A1. Badana stal zawiera 0,032 \% N. W przypadku azotu PN-EN 14811+A1 nie określa maksymalnej jego zawartości. Maksymalna zawartość azotu w stali R260 stosowanej na szyny kolejowe, wg PN-EN 13674-1 wynosi 0,010 \%. Oznacza to, że $\mathrm{w}$ badanej stali dopuszczalna ilość azotu, została trzykrotnie przekroczona. Podwyższona zawartość azotu obniża plastyczność stali, co może objawiać się zwiększoną kruchością związaną również z wydzielaniem się azotków w postaci wtrąceń niemetalicznych. Przedmiotowa szyna ma strukturę perlityczną (rys. 3), a jej wytrzymałość na rozciąganie, wydłużenie i twardość mają wartości wymagane przez PN-EN 14811+A1 (tab. II). Pozytywne wyniki badań próbek pobranych z główki szyny nie dały podstawy do wskazania przyczyny ich pękania. Kolejne badania wykonano na próbkach pobranych w kierunku prostopadłym do kierunku walcowania szyny. Również w tym przypadku próba rozciągania dała wyniki pozytywne, wytrzymałość na rozciąganie $\mathrm{Rm}=932 \mathrm{MPa}$ i wydłużenie $\mathrm{A}=11,6 \%$, a więc wyniki spełniające wymagania PN-EN 14811+A1. Dopiero próba udarności wykonana na próbkach pobranych z szyjki, prostopadle do kierunku walcowania szyny (karb nacięto zgodnie z kierunkiem walcowania), ujawniła właściwość sprzyjającą kruchemu pękaniu. Praca łamania próbek w temperaturze $20^{\circ} \mathrm{C}$ nie przekroczyła wartości 6,9 J. W celu znalezienia przyczyn tak małej wartości pracy łamania wykonano badania fraktograficzne i mikrostrukturalne.

Tablica I. Skład chemiczny pękniętej szyny ze stali R260

Table I. Chemical composition of steel rail cracked R260

\begin{tabular}{|c|c|c|c|c|c|c|}
\hline \multirow{2}{*}{ Badania/norma } & \multicolumn{7}{|c|}{ Procentowy udział pierwiastków, \% } \\
\cline { 2 - 8 } & $\mathbf{C}$ & Si & Mn & P & S & N \\
\hline Badania własne & 0,630 & 0,306 & 0,868 & 0,013 & 0,019 & 0,032 \\
\hline EN-EN 14811+A1 & $0,60-0,82$ & $0,13-0,60$ & $0,65-1,25$ & max. 0,030 & $\max .0,030$ & - \\
\hline
\end{tabular}


Tablica I. Własności mechaniczne pękniętej szyny ze stali R260

Table I. The mechanical properties of the broken rail steel R260

\begin{tabular}{|c|c|c|c|}
\hline Badania/norma & $\begin{array}{c}\text { Wytrzymałość na rozciąganie } \\
\mathbf{R}_{\mathbf{m}} \\
\mathbf{M P a}\end{array}$ & $\begin{array}{c}\text { Wydłużenie względne } \\
\mathbf{A} \\
\%\end{array}$ & $\begin{array}{c}\text { Twardość } \\
\text { HBW }\end{array}$ \\
\hline Badania własne & $941-960$ & $18,3-26,7$ & $274-300$ \\
\hline PN-EN 14811+A1 & $880(\min )$. & 10,0 (min.) & $260-300$ \\
\hline
\end{tabular}

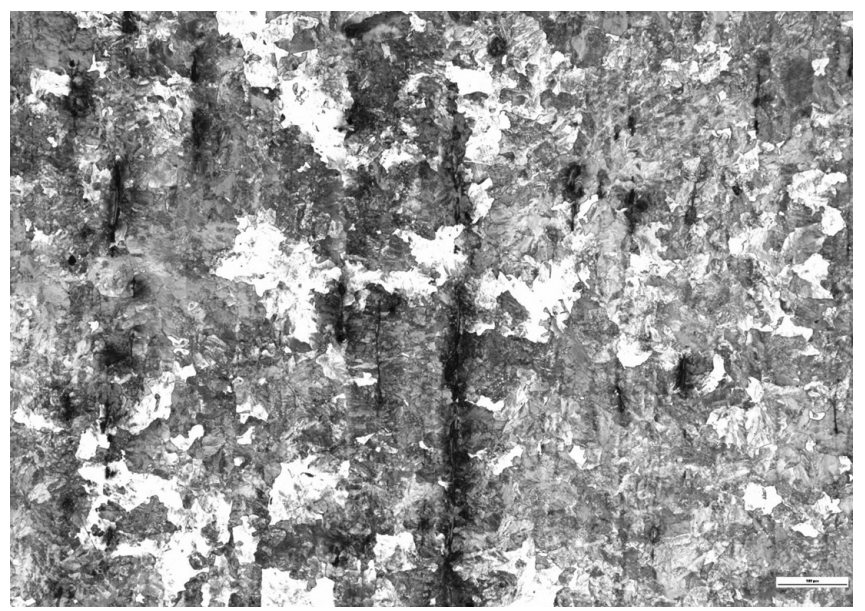

Rys. 3. Perlityczna struktura szyny tramwajowej pękniętej podczas spawania termitowego $w$ przekroju poprzecznego P2p (rys .6), powiększenie $x 10$

Fig. 3. Pearlite structure tram rails broken during thermite welding in cross-section of P2p (Fig .6), mag. x10

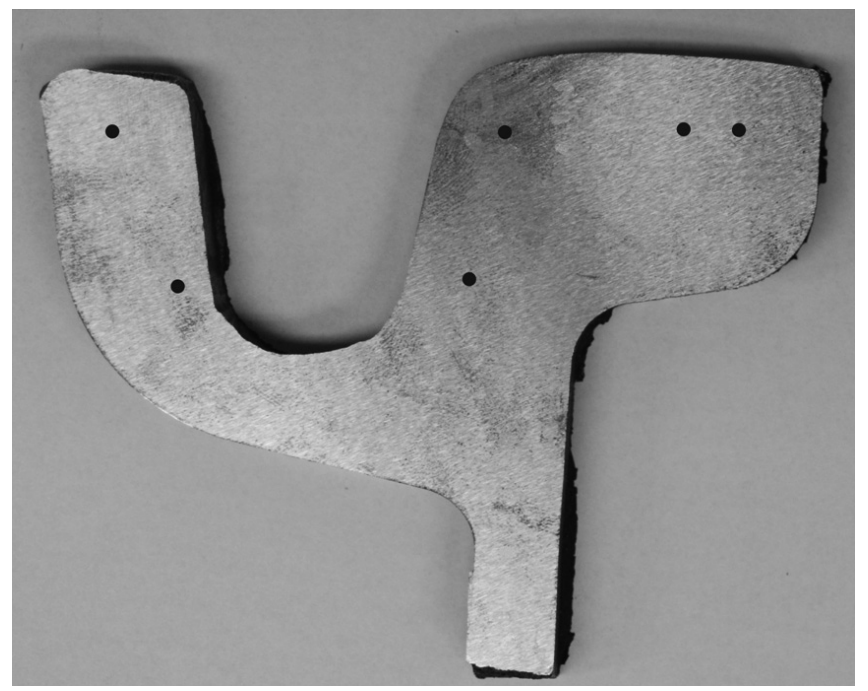

Rys. 4. Przekrój rowkowej szyny tramwajowej z zaznaczonymi punktami pomiaru twardości HBW

Fig. 4. The cross-section groove tram rails with measurement points hardness HBW

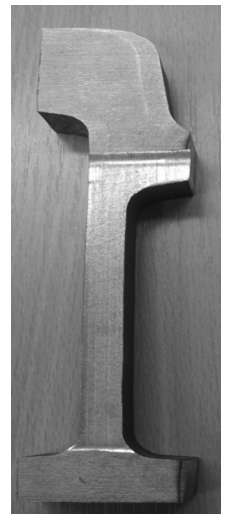

Rys. 5. Próbka do próby rozciągania pobrana w kierunku prostopadłym do kierunku walcowania szyny

Fig. 5. A sample for tensile test taken in a direction perpendicular to the rolling direction of the rail

\section{Badania fraktograficzne i mikrostrukturalne}

Badania metalograficzne wykonano na czterech próbkach pobranych z szyn spawanych termitowo z miejsc określonych na rysunku 6. Próbki zostały oznaczone symbolami: P1 (przełom ze strefą wpływu ciepła - SWC), P2 (przełom bez SWC) oraz PU (próbka po próbie udarnościowej). Dla próbki P2 wykonano zgłady metalograficzne w dwóch płaszczyznach, zgodnie z rysunkiem 6 .

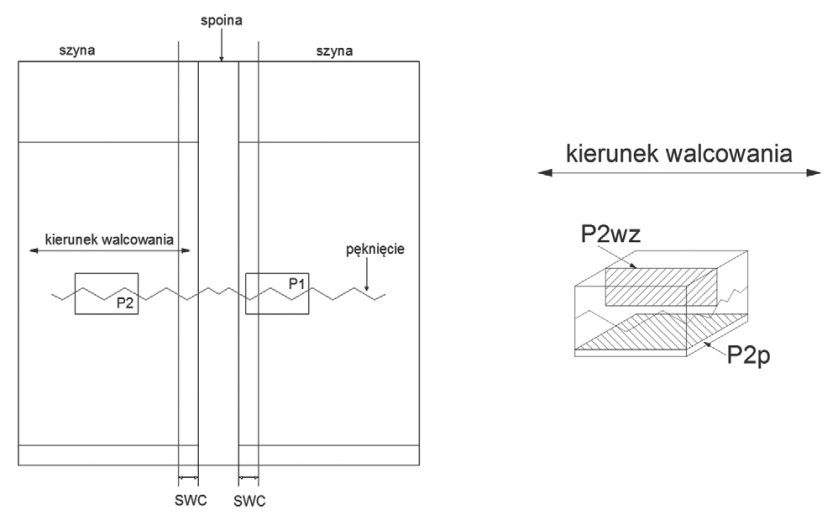

Rys. 6. Miejsca pobrania próbek do badań fraktograficznych i mikrostrukturalnych oraz oznaczenia płaszczyzn zgładów metalograficznych

Fig. 6. Places samples taken for fractography test, microstructural test and marks planes metallographic specimens

\section{Badania fraktograficzne}

Badania przełomów przeprowadzono na mikroskopie elektronowym Hitachi SU-70. Wykonano badania przełomów próbek P1 i PU. Przykładowe wyniki przedstawiono na rysunkach 7 i 8.

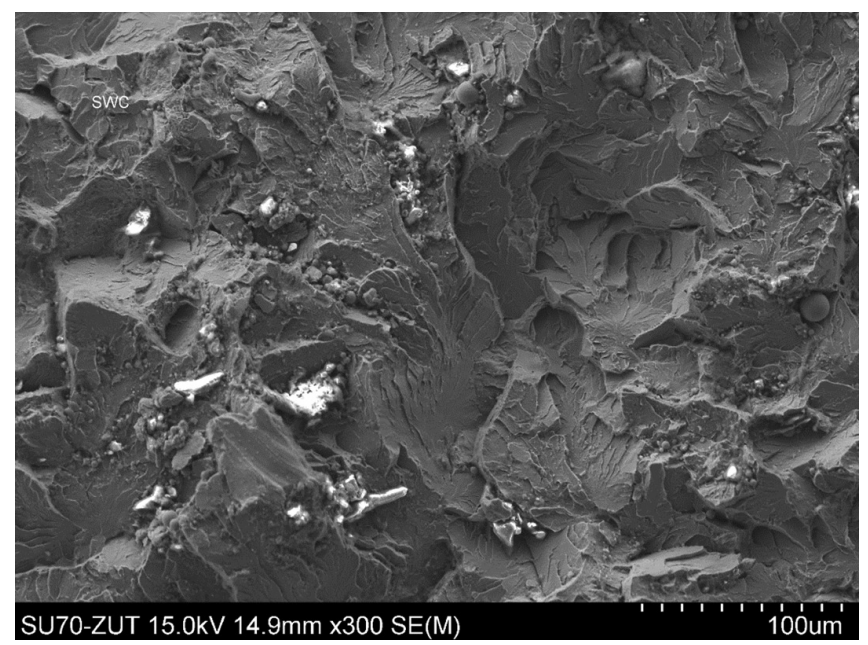

Rys. 7. Powierzchnia przełomu próbki $\mathrm{P} 1$, SWC

Fig. 7. Surface sample - fracture $P 1, H A Z$ 


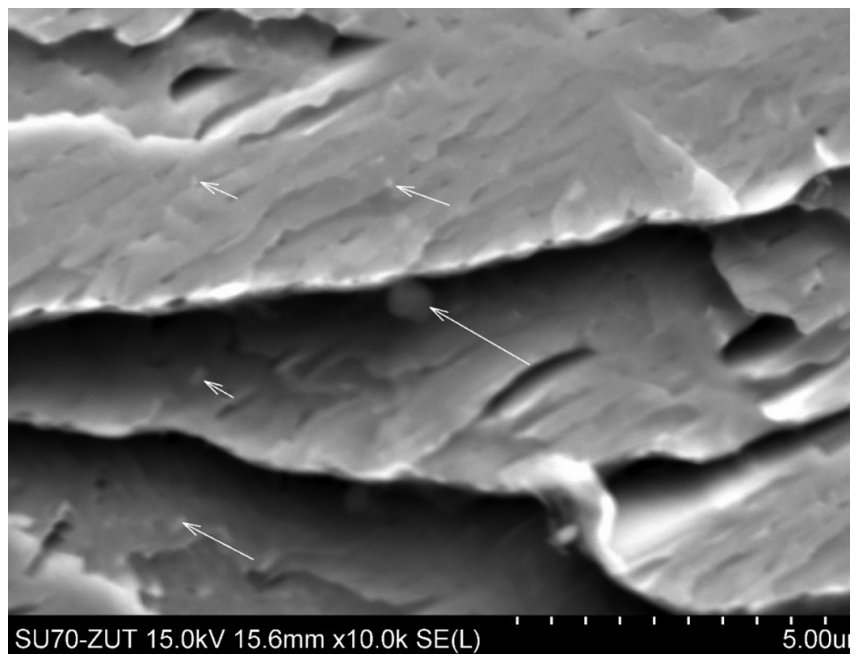

Rys. 8. Powierzchnia przełomu próbki udarnościowej PU Fig. 8. Surface sample - after impact test - fracture PU

$\mathrm{Na}$ obserwowanych przełomach stwierdzono mechanizm pękania trans krystalicznego, przebiegającego poprzez ziarna materiału, w tym przypadku ziarna perlitu. Nie stwierdzono występowania plastycznego odkształcenia materiału, co potwierdza, ze jest to przypadek kruchego pękania. Stwierdzono obecność dużej ilości wtrąceń niemetalicznych, których koncentracja widoczna jest na granicach ziaren. Widoczne na rysunku 7 wtrącenia są najprawdopodobniej siarczkami oraz tlenkami. Na rysunku 8 widoczne są z kolei tlenki o charakterystycznym kulistym kształcie umiejscowione zarówno na granicach jak i wewnątrz ziaren co powoduje kruche pękanie trans krystaliczne materiału wzdłuż płaszczyzn na których się one lokują.

\section{Mikroskopia elektronowa}

Po wykonaniu obrazów nie trawionych powierzchni próbek poddano je trawieniu odczynnikiem Nital i ponownie badano mikrostrukturę materiału. Za pomocą mikroskopu SEM rejestrowano obrazy elektronów wtórnych (SEI) oraz elektronów wstecznie rozproszonych (BEI). Badania składu chemicznego przeprowadzono metodą mikroanalizy rentgenowskiej z dyspersją energii EDS (EnergyDispersiveSpectrometry) przy użyciu systemu Noran 7 firmy ThermoScientific. Przykładowe wyniki przedstawiono na rysunkach 9 i 10.

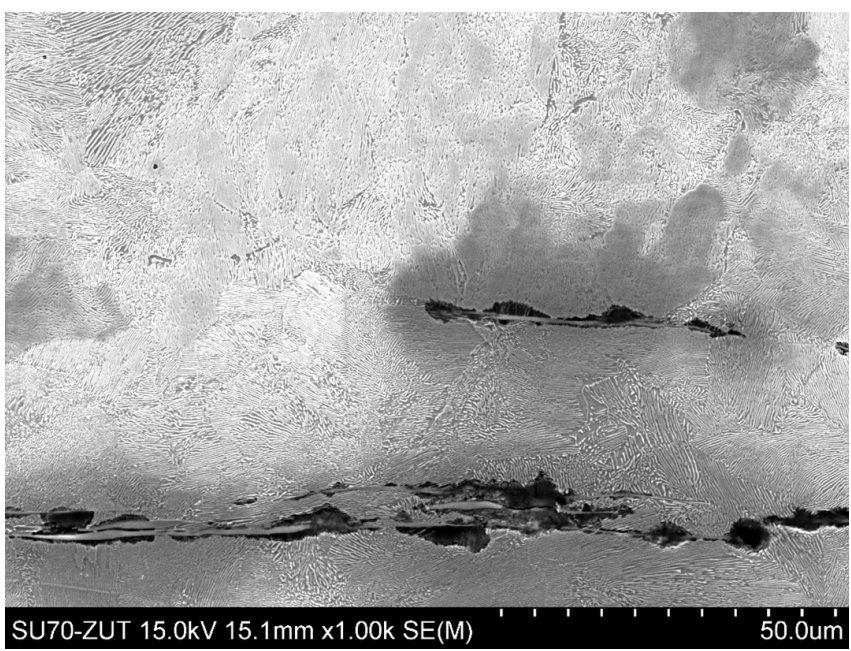

Rys. 9. Mikrostruktura powierzchni przekroju poprzecznego, próbka P2p (SEI)

Fig. 9. The microstructure of the cross section area, sample P2p (SEI)

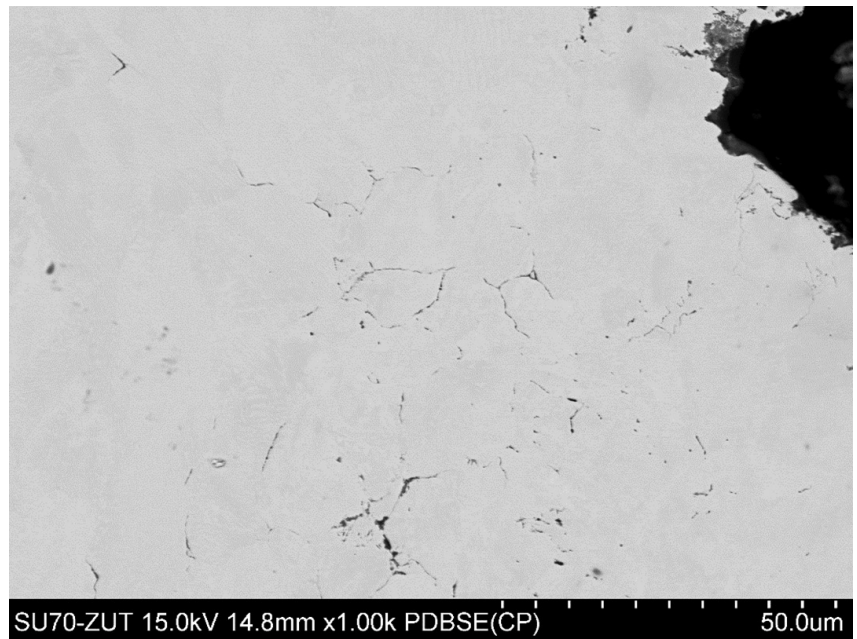

Rys. 10. Mikrostruktura powierzchni przekroju poprzecznego, próbka P2p (SEI)

Fig. 10. The microstructure of the cross section area, sample P2p (SEI)

Obserwacje mikroskopowe pozwoliły na stwierdzenie, że wszystkie z badanych próbek posiadają strukturę perlityczną. Materiał poddany badaniu zawiera bardzo duże ilości wtrąceń niemetalicznych (siarczków oraz tlenków) o zróżnicowanej wielkości. Tworzą one pasma wydzieleń, których koncentracja widoczna jest szczególnie w środkowej części przekroju szyjki szyny (rys. 9). Ponadto na rysunku 10 ujawniono wydzielenia dużej ilości tlenków na granicach ziaren perlitu, których koncentracja występuje w obszarze powstałego w materiale pęknięcia. Wynik ten potwierdziła analiza EDS w obszarach przekroju tej samej próbki, w punktach pokazanych na rysunku 11. Przykładowy wynik przedstawiono na rysunku 12 . Nie stwierdzono podwyższonej zawartości tlenu w materiale rodzimym oddalonym od wydzieleń (pkt. 4 rys. 11).

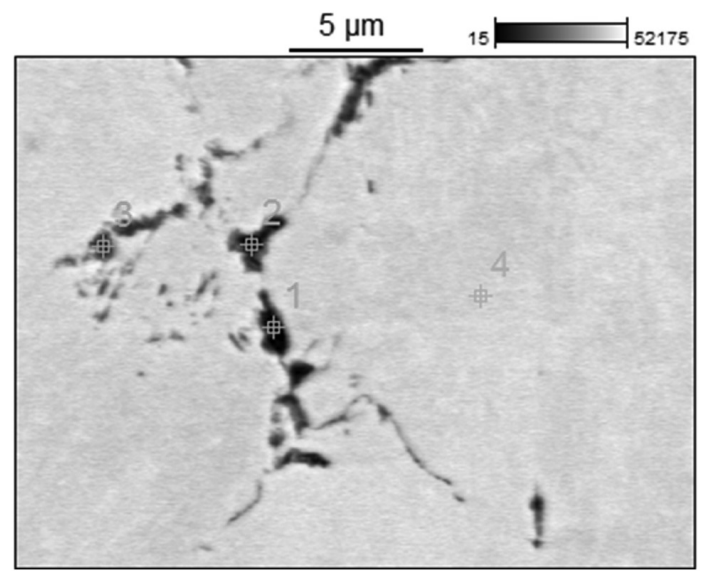

Rys. 11. Powierzchnia przekroju poprzecznego $2 \mathrm{wz}$ w sąsiedztwie pęknięcia (BEI) z punktami pomiaru EDS

Fig. 11. The cross section area near the crack (BEI) of the measuring points EDS

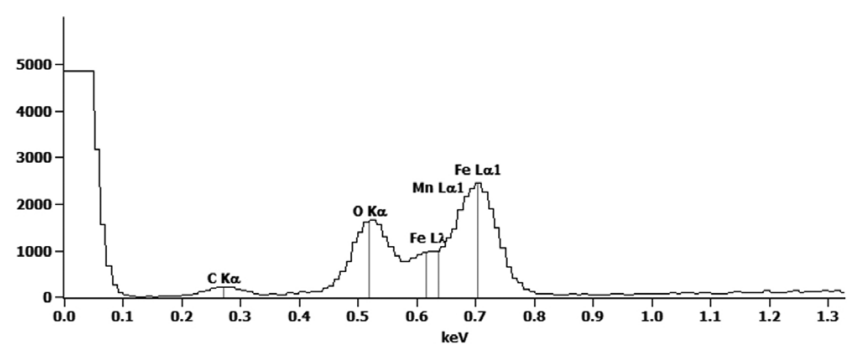

Rys. 12. Widmo EDS wykonane w punkcie 2 (Rys. 11)

Fig. 12. Widmo EDS wykonane w punkcie 2 (Rys. 11) 


\section{Podsumowanie}

Bezpośrednią przyczyną pękania szyn są naprężenia. Pęknięcie szyny pokazane na rysunku 1 stwierdzono bezpośrednio po jej spawaniu. Oznacza to, że powstało ono na skutek działania naprężeń spawalniczych (cieplnych). Różne objętości główki, szyjki i stopki przypadające na jednostkę długości szyny powodują, że szyna w tych obszarach będzie nagrzewała się i chłodziła z innymi prędkościami. W wyniku tego powstało naprężenie o wartości wystarczającej do spowodowania pęknięcia szyny. Podobnie jest ze szklanką o grubym dnie i cienkiej ściance, która pęka po szybkim napełnieniu jej wrzątkiem.

Wyniki badań składu chemicznego i wytrzymałości doraźnej przedmiotowej szyny spełniają wymagania PN-EN $14811+A 1$. Na tej podstawie można sądzić, że u podłoża tak dużej ilości pęknięć szyn nie leży ich materiał. Jednakże, dodatkowe badania mikrostrukturalne oraz udarności, wykonane w miejscu pęknięcia szyjki szyny, ujawniły właściwości sprzyjające powstawaniu i rozprzestrzenianiu się pęknięć. Praca łamania próbek, z karbem naciętym wzdłuż kierunku walcowania szyny, nie przekraczająca kilku J i liczne wtrącenia niemetaliczna o charakterze tlenkowym i siarczkowym ujawnione na zdjęciach mikrustruktury z pewnością należą do czynników obniżających wartość naprężeń, przy których mogą powstać pęknięcia.

Z porównania zakresu badań jakim podlegają szyny kolejowe (PN-EN 13674-1 ) i szyny tramwajowe (PN-EN 14811+A1) widać, że w przypadku szyn tramwajowych jest on znacznie węższy. Na przykład, dla szyn tramwajowych nie są w normie (PN-EN 14811+A1) przewidziane badania zmęczeniowe.

Każde pęknięcie przed dopuszczeniem torowiska do eksploatacji powinno być ujawnione i bezwzględnie usunięte. W przeciwnym razie, pod działaniem dynamicznych obciążeń pochodzących od przejeżdżających tramwajów, będzie się rozwijało i ostatecznie powstanie pęknięcie w skali makro.

Mając na uwadze tak liczne pęknięcia szyn tramwajowych, odnotowane w ostatnich latach na nowo budowanych lub modernizowanych torowiskach, autorzy wskazuja na konieczność podjęcia prac, celem których będzie zaproponowanie odpowiednich zmian w obowiązujących przepisach, na przykład dotyczących zakresu badań szyn przed dopuszczeniem ich do montażu na torowisku, badań spoin po ich wykonaniu oraz uprawnień spawaczy i firm spawających szyny tramwajowe.

\section{Literatura}

[1] Kądziołka A, „Termitowe spawanie - rys historyczny, zmiany, postęp", IV Ogólnopolska Konferencja Naukowo-Techniczna, Spawalnictwo dróg szynowych - jakość, niezawodność, bezpieczeństwo, Bochnia, 2010.

[2] Kędra Z., "Technologia robót torowych" Wydawnictwo PG, Gdańsk, 2015.

[3] Opolska-lgańska H., Kądziołka A., „Zapewnienie jakości w spawalnictwie nawierzchni szynowej w świetle ustanowionych oraz projektowanych norm europejskich", III Ogólnopolska Konferencja Naukowo-Techniczna, Spawalnictwo dróg szynowych oraz materiały, wykonawstwo, odbiory, Warszawa-Bochnia, 2007.

[4] Mikłaszewicz I., „Wykonanie i badanie kolejowych złączy szynowych", Problemy Kolejnictwa, 158, s. 35-49, 2013.

[5] Dobrzański L., A., Podstawy nauki o materiałach i metaloznawstwo. Materiały inżynierskie z podstawami projektowania materiałowego, Wydawnictwo Naukowo-Techniczne, Warszawa, 2002.

[6] Bolanowski P., „Właściwości złącza spawanego szyny podsuwnicowej spawanej metodą 111", Przegląd Spawalnictwa, nr 7, 2014, s. 9-16.

[7] WWW.expressilustrowany.pl/artykul/856413

[8] Lesiński, K.J., "O przyczynach pękania spawanych styków oraz regenerowanych szyn", Biuletyn Instytutu Spawalnictwa, nr 5, 1999, s. 152-155

[9] Bogdaniuk B., Towpik K., „Budowa, modernizacja i naprawy dróg kolejowych", Kolejowa Oficyna Wydawnicza, Warszawa, 2010. 